\title{
Poor clinical performance of the Wessex porcine heart valve bioprosthesis at nine years' follow up
}

\author{
Aquilino Hurlé, J Francisco Nistal, José M Revuelta
}

\begin{abstract}
Objective-To assess the long term performance of the Wessex porcine bioprostheses implanted in a consecutive series of patients.

Design-A retrospective case series.

Patients-Between January 1985 and July 1991, 184 Wessex bioprostheses (78 mitral, 102 aortic, and 4 tricuspid) were implanted in 150 patients. The patients were $55 \%(83 / 150)$ male and $45 \%(67 / 150)$ female; mean age was 60 (SD 10) years.

Results-Hospital mortality was $9 \cdot 3 \%$ (14/150). Total follow up was 696 patientyears (mean 4.7 years per patient). Linearised rates (events per 100 patientyears (SEM)) for postoperative complications for patients with isolated mitral valve replacement, isolated aortic valve replacement, and multiple valve replacement were, respectively: late mortality: $4.7(1.6), 3.3(0.9)$, and 4.9 (1.9); thromboembolism: $5.8(1.8), 3.0(0.9)$, and 2.8 (1.4); valve thrombosis: $1.0(0.7), 0.3$ $(0.3)$, and $0.7(0.7)$; structural failure: 5.8 $(1 \cdot 7), 1.9(0 \cdot 7)$, and $7 \cdot 1(2 \cdot 2)$. Actuarial freedom from complications at nine years ( $70 \%$ confidence interval) was: late mortality: 61 (9)\%, 57 (13)\%, and 59 (12)\%; thromboembolism and valve thrombosis: $71(9) \%, 79(6) \%$, and $81(8) \%$; structural failure: $33(14) \%, 50(16) \%$, and $12(14) \%$; all valve related morbidity/mortality: 31 (10)\%, $21(11) \%$, and 7 (9)\%. Stent fractures appeared in 11 of 17 explanted prostheses; actuarial freedom from stent fracture at nine years was $66(12) \%$.

Conclusions-The Wessex bioprosthesis is associated with high thrombogenicity, early structural dysfunction, and a high valve related morbidity/mortality which justifies very close follow up of patients fitted with them.
\end{abstract}

(Heart 1997;77:319-324)

Cardiovascular

Surgery, University

Hospital "Marqués de

Valdecilla", University

of Cantabria,

Santander, Spain

A Hurlé

J F Nistal

J M Revuelta

Correspondence to:

Dr J F Nistal, Servicio de

Cirugía Cardiovascular,

Hospital Universitario

"Marqués de Valdecilla",

E-39008 Santander, Spain.

Accepted for publication

25 October 1996 for clinical use in the United Kingdom in the early 1980s. Initial experimental studies showed a good in vitro performance, ${ }^{1}$ and the results obtained in the first clinical reports were encouraging. ${ }^{2}$ However, despite the fact that substantial numbers of these valves have now been implanted, mainly in Great Britain but also in other European countries, its clinical performance in the mid to long term is not well defined as published data are scarce. In this retrospective patient oriented study we report our experience with the Wessex valve at nine years' follow up.

\section{Methods}

Between January 1985 and July 1991, 150 patients received a total of 184 Wessex bioprostheses (78 mitral, 102 aortic, 4 tricuspid) at the University Hospital "Marqués de Valdecilla". Forty six patients underwent isolated mitral valve replacement (MVR), 72 had isolated aortic valve replacement (AVR), and the remaining 32 patients received more than one prosthesis (MultiVR): mitral and aortic in 28 cases, mitral and tricuspid in two cases, and triple valve replacement in two cases. All patients were operated under extracorporeal circulation and moderate systemic hypothermia. Myocardial protection was achieved with the antegrade infusion of cold cardioplegic solution and with topical cooling of the heart with cold saline.

Postoperative oral anticoagulation was not given routinely. Only patients with risk factors for thromboembolism (atrial fibrillation with giant atria, left atrial thrombi, etc) and those who developed a thromboembolic episode were subsequently anticoagulated with oral acenocoumarol.

This retrospective patient oriented study did not exclude any patient receiving a Wessex bioprosthesis in our unit during the time frame of the survey. Operative data were collected from the medical records. Follow up data were obtained from the patients on their regular visits to the outpatient clinics or by telephone interviews with them or their relatives. The closing interval (time elapsed for the collection of follow up information from all the patients) was two months. Follow up was $98 \cdot 7 \%$ complete, with missing information in only two cases. The guidelines of the liaison committee of the American Association for Thoracic Surgery, the Society of Thoracic Surgeons, and the European Association of CardioThoracic Surgery for reporting morbidity and mortality after cardiac valvar operations were observed. ${ }^{3}$

Complications appearing with a non-biased time course were expressed by linearised rates. Actuarial analysis was performed using the 
Table 1 Associated surgery

\begin{tabular}{|c|c|c|c|}
\hline \multirow[b]{2}{*}{ Procedure } & \multicolumn{3}{|l|}{ Group } \\
\hline & $\begin{array}{l}M V R \\
(n=46)\end{array}$ & $\begin{array}{l}A V R \\
(n=72)\end{array}$ & $\begin{array}{l}\text { MultiVR } \\
(n=32)\end{array}$ \\
\hline Coronary bypass & 3 & 8 & - \\
\hline Aortic surgery & - & 5 & 1 \\
\hline Conservative mitral & - & 1 & - \\
\hline Conservative tricuspid & 10 & - & 4 \\
\hline LA Lig/thrombectomy & 3 & - & 2 \\
\hline LV aneurysmectomy & 1 & - & - \\
\hline Pericardiectomy & - & - & 1 \\
\hline
\end{tabular}

MVR, mitral valve replacement; AVR, aortic valve replacement; MultiVR, multiple valv replacement; LA lig, ligation of left atrial appendage; LV, left ventricular.

Table 2 Hospital mortality

\begin{tabular}{llll}
\hline & \multicolumn{2}{l}{ Group } & \\
\cline { 2 - 4 } Causes & $\begin{array}{l}\text { MVR } \\
(n=46)\end{array}$ & $\begin{array}{l}A V R \\
(n=72)\end{array}$ & $\begin{array}{c}\text { MultiVR } \\
(n=32)\end{array}$ \\
\hline $\begin{array}{l}\text { Low cardiac output } \\
\text { Haemorrhage }\end{array}$ & 2 & 2 & 1 \\
Arrhythmia & - & 1 & $\frac{1}{1}$ \\
Endocarditis & - & 2 & $\frac{1}{1}$ \\
Sepsis & 1 & 1 & -
\end{tabular}

$\overline{\text { MVR, mitral replacement; AVR, aortic valve replacement; MultiVR, multiple valve replace- }}$ ment. ${ }^{\star} W$ ithin 30 days of surgery.

Kaplan-Meier method. ${ }^{4}$ Comparisons between actuarial estimates were done by using normal distribution. Continuous variables were compared using a two tailed Student $t$ test. Categorical data were compared by a $2 \times 2$ contingency table or a $\chi^{2}$ test, corrected if appropriate by Yate's formula or Fisher's exact test.

\section{Results}

The mean age of the whole group of patients was 60 (SD 10) years (range 32 to 79 years) and was similar for the three cohorts. Females predominated in the MVR group (70\%, $32 / 46)$, males in the AVR group $(76 \%, 55 / 72)$, and both sexes were equally distributed in the MultiVR group. The aetiology of valvar disease was predominantly rheumatic in the MVR and MultiVR groups (54\%, 25/46; and $66 \%, 21 / 32$, respectively) and degenerative in the AVR group (76\%, 43/72). Dysfunction of a previous bioprosthesis was the indication for surgery in $19 \%(9 / 46)$ of the MVR patients and $25 \%(8 / 32)$ of the MultiVR patients.

Thirty four patients $(74 \%, 34 / 46)$ in the MVR group were in atrial fibrillation preoperatively. Six patients from this group (13\%, 6/46) suffered thromboembolic episodes
Table 4 Late mortality

\begin{tabular}{llll}
\hline & \multicolumn{2}{l}{ Group } & \\
\cline { 2 - 4 } Causes & $\begin{array}{l}\text { MVR } \\
(n=46)\end{array}$ & $\begin{array}{l}\text { AVR } \\
(n=72)\end{array}$ & $\begin{array}{l}\text { MultiVR } \\
(n=32)\end{array}$ \\
\hline $\begin{array}{l}\text { Congestive heart failure } \\
\begin{array}{l}\text { Stroke/peripheral } \\
\text { embolism }\end{array}\end{array}$ & 1 & - & 1 \\
$\begin{array}{l}\text { Endocarditis } \\
\text { Arrhythmia }\end{array}$ & 2 & - & 3 \\
AIDS & 1 & - & - \\
$\begin{array}{l}\text { Neoplastic disease } \\
\text { Death at reoperation }\end{array}$ & 1 & 1 & - \\
$\begin{array}{l}\text { Sudden domiciliary } \\
\text { death }\end{array}$ & 1 & - & 1 \\
$\begin{array}{l}\text { Others } \\
\text { Unknown }\end{array}$ & 2 & 2 & - \\
\hline
\end{tabular}

MVR, mitral valve replacement; AVR, aortic valve replacement; MultiVR, multiple valve replacement.

before surgery, two of them being in sinus rhythm (septic embolisation from mitral valve endocarditis in both cases). The great majority of the AVR patients $(92 \%, 66 / 72)$ were in sinus rhythm before surgery, and only six patients from this group $(8 \%, 6 / 72)$ had previous thromboembolic episodes (because of valve endocarditis in two cases). In the MultiVR group, 21 patients $(66 \%, 21 / 32)$ were in atrial fibrillation preoperatively and five (four in atrial fibrillation and one with infective endocarditis) sustained thromboembolic events before surgery.

The most common sizes of the valves implanted were $29 \mathrm{~mm}$ in the mitral position, $23 \mathrm{~mm}$ in the aortic position, and $31 \mathrm{~mm}$ in the tricuspid position. Concomitant surgical procedures are shown in table 1 .

The total follow up was 696 patient-years (191 for MVR, 364 for AVR, and 141 for MultiVR), with a mean of 4.7 years per patient ( $4 \cdot 1$ for MVR, $5 \cdot 2$ for AVR, and 4.4 for MultiVR).

MORTALITY

Fourteen patients (five in the MVR group, six in the AVR group, and three in the MultiVR group) died in hospital or within 30 days of surgery. The global hospital mortality was $9 \cdot 3 \%(14 / 150)(10 \cdot 9 \%, 5 / 46$ for MVR; $8 \cdot 3 \%$, $6 / 72$ for AVR; $9 \cdot 4 \%, 3 / 32$ for MultiVR). The causes of hospital mortality are shown in table 2. Twenty eight patients died late postoperatively (table 3 ), the causes of death being summarised in table 4. Fifteen of these deaths were considered to be valve related (table 3 ).

Actuarial probabilities of survival at nine

Table 3 Complications

\begin{tabular}{|c|c|c|c|c|c|c|c|c|c|}
\hline \multirow[b]{3}{*}{ Complication } & \multicolumn{9}{|l|}{ Group } \\
\hline & \multicolumn{3}{|l|}{$M V R$} & \multicolumn{3}{|l|}{$A V R$} & \multicolumn{3}{|l|}{ MultiVR } \\
\hline & Patients & Events & $L R(S D)$ & Patients & Events & $L R(S D)$ & Patients & Events & $L R(S D)$ \\
\hline Late mortality & 9 & 9 & $4 \cdot 7(1 \cdot 6)$ & 12 & 12 & $3.3(0.9)$ & 7 & 7 & $4.9(1.9)$ \\
\hline Valve related mortality & 6 & 6 & $3 \cdot 1(1 \cdot 3)$ & 4 & 4 & $1 \cdot 1(0 \cdot 6)$ & 5 & 5 & $3.6(1.6)$ \\
\hline Thromboembolism & 7 & 11 & $5.8(1.8)$ & 10 & 11 & $3.0(0.9)$ & 4 & 4 & $2 \cdot 8(1 \cdot 4)$ \\
\hline Lethal & 2 & 2 & $1.0(0.7)$ & - & - & - & 3 & 3 & $2 \cdot 1(1 \cdot 2)$ \\
\hline Permanent impairment & 3 & 3 & $1.6(0.9)$ & 6 & 6 & $1 \cdot 6(0 \cdot 7)$ & 1 & 1 & $0.7(0.7)$ \\
\hline Valve thrombosis & 2 & 2 & $1.0(0.7)$ & $1^{\star}$ & 1 & $0.3(0.3)$ & 1 & 1 & $0.7(0.7)$ \\
\hline Prosthetic endocarditis & 2 & 2 & $1.0(0.7)$ & 5 & 5 & $1 \cdot 4(0.6)$ & 1 & 1 & $0.7(0.7)$ \\
\hline Lethal & 2 & 2 & $1.0(0 \cdot 7)$ & 4 & 4 & $1 \cdot 1(0.5)$ & $i$ & i & $0.7(0.7)$ \\
\hline Structural deterioration & 11 & 11 & $5 \cdot 8(1.7)$ & 7 & 7 & $1.9(0.7)$ & 10 & 10 & $7 \cdot 1(2 \cdot 2)$ \\
\hline Non-structural dysfunction & 2 & 2 & $1.6(0.9)$ & 5 & 5 & $1 \cdot 6(0 \cdot 7)$ & 4 & 4 & $3.5(1.6)$ \\
\hline Reoperation & 12 & 12 & $6 \cdot 3(1 \cdot 8)$ & 10 & 10 & $2.7(0.9)$ & 9 & 9 & $6 \cdot 4(2 \cdot 1)$ \\
\hline
\end{tabular}




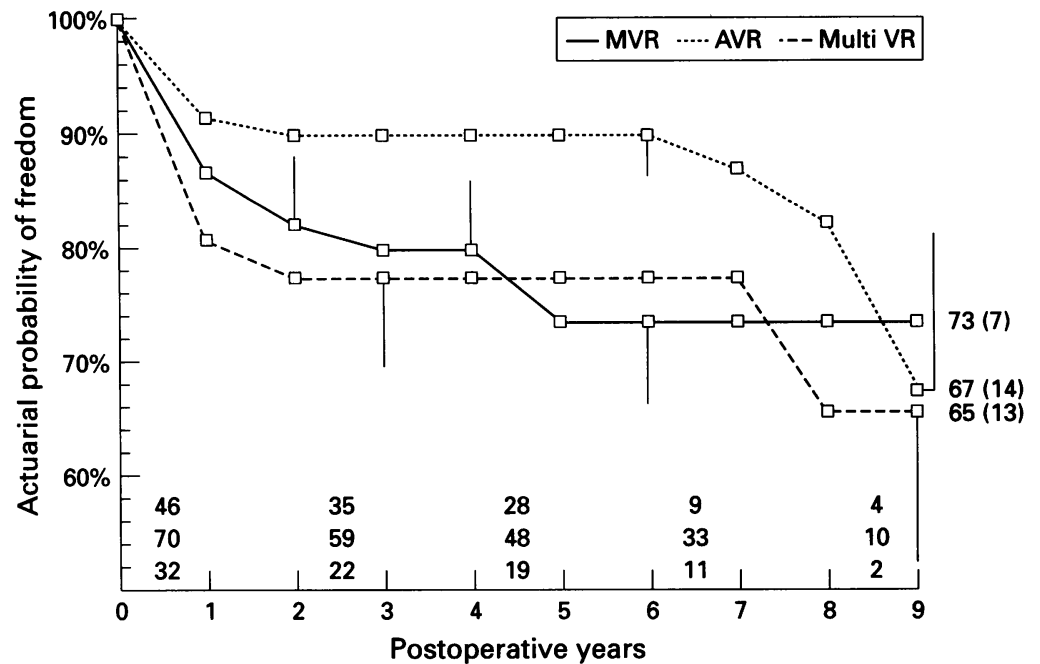

Figure 1 Freedom from valve related mortality. Actuarial probability at 9 years' follow up. Error bars $=70 \%$ confidence interval.

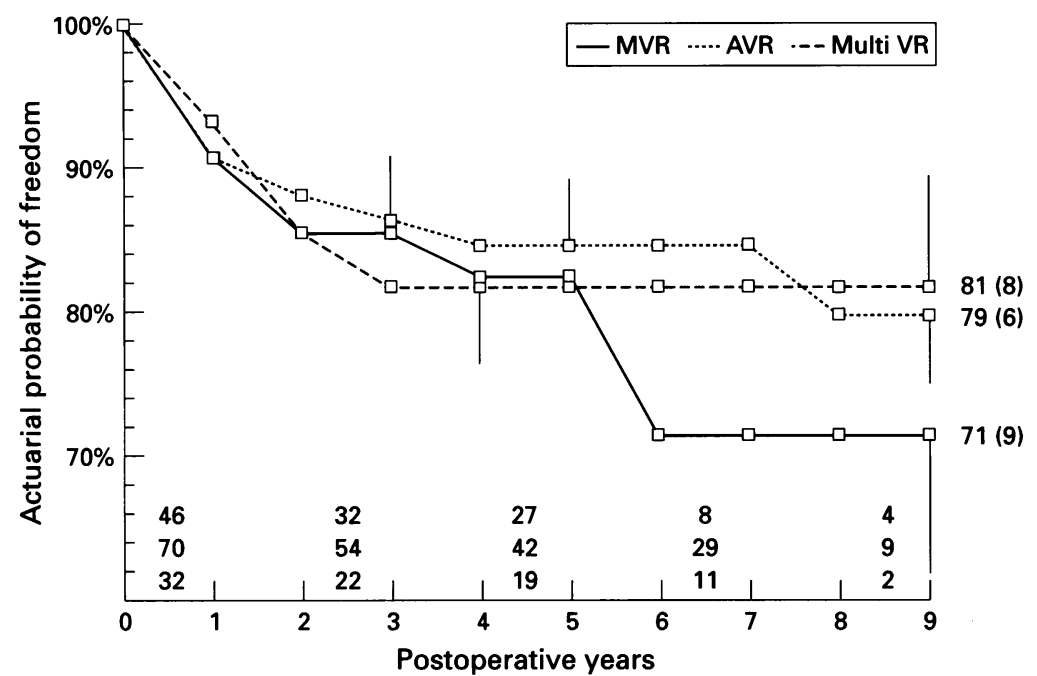

Figure 2 Freedom from thromboembolism or valve thrombosis. Actuarial probability at 9 years' follow up. Error bars $=70 \%$ confidence interval.

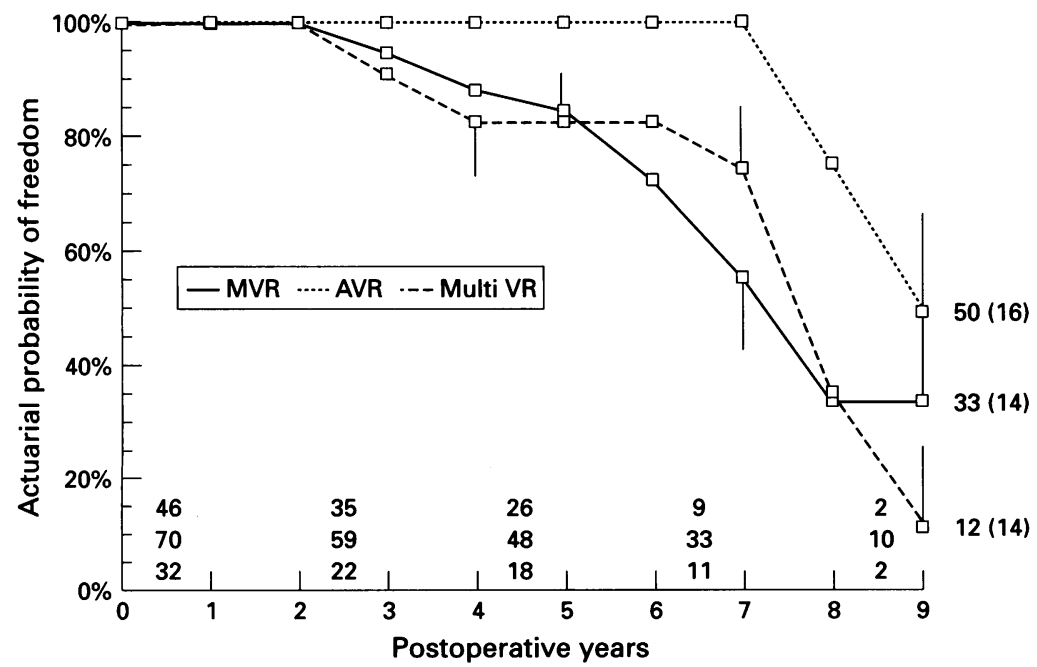

Figure 3 Freedom from structural deterioration. Actuarial probability at 9 years' follow up. Error bars $=70 \%$ confidence interval. years of follow up (70\% confidence intervals in parentheses) were 61 (9)\% for MVR, 57 (13)\% for AVR, and 59 (12)\% for MultiVR. Actuarial probabilities of freedom from valve related death at nine years were 73 (7)\% for MVR, 67 (14)\% for AVR, and 65 (13)\% for the MultiVR (fig 1).

THROMBOEMBOLISM AND VALVE THROMBOSIS

Overall, 21 patients sustained a total of 26 thromboembolic events, which were lethal on five occasions and caused some degree of permanent impairment in 10 patients (table 3 ). Linearised rates for thromboembolism, death of thromboembolic origin, and thromboembolism resulting in permanent impairment are shown in table 3.

Valve thrombosis occurred on four occasions, requiring reoperation for substitution of the thrombosed prostheses in all cases, and being the cause of death in one patient (table 3). Linearised rates for valve thrombosis are also shown in table 3. Actuarial estimates of freedom from thromboembolism and valve thrombosis at nine years of follow up $(70 \%$ CI) were 71 (9)\% for MVR, 79 (6)\% for AVR, and 81 (8) $\%$ for MultiVR (fig 2).

\section{PROSTHETIC ENDOCARDITIS}

There were eight cases of prosthetic endocarditis causing the deaths of five patients (table 3). Table 3 also shows the linearised rates for prosthetic endocarditis. Actuarial probabilities of freedom from prosthetic endocarditis at nine years of follow up $(70 \% \mathrm{CI})$ were 95 (3)\% for MVR, 88 (6)\% for AVR, and 96 (3)\% for MultiVR.

\section{STRUCTURAL DETERIORATION}

Twenty eight cases of structural deterioration were found echocardiographically or at heart catheterisation. This was the main indication for reoperation in 20 patients (table 3). Actuarial freedom from this complication at nine years of follow up $(70 \% \mathrm{CI})$ was 33 (14)\% for MVR, 50 (16)\% for AVR, and 12 (14)\% for MultiVR (fig 3).

Forty valves were explanted during the follow up and 17 were recovered for study. Stent fractures were present in 11 of these (nine aortic and two mitral), which were explanted at a mean of 70 (SD 31) months (range 10 to 101 months) after the initial surgery (fig 4). All nine aortic prostheses were explanted for various reasons other than stent fracture. Both mitral valves presented severe regurgitation due to a tear of a cusp and the deformity produced by the ruptured stent. All affected specimens presented multiple fractures (mean of 3.6 (SD 1.6) per valve), which characteristically appeared at the base of the post arch or at the commissural portion of the basal ring. The estimated actuarial probability of freedom from stent fracture in either mitral or aortic prostheses at nine years of follow up $(70 \% \mathrm{CI})$ was $66(12) \%$.

\section{NON-STRUCTURAL DYSFUNCTION}

Thirteen instances of non-structural dysfunction (haemolysis and periprosthetic leak) were 


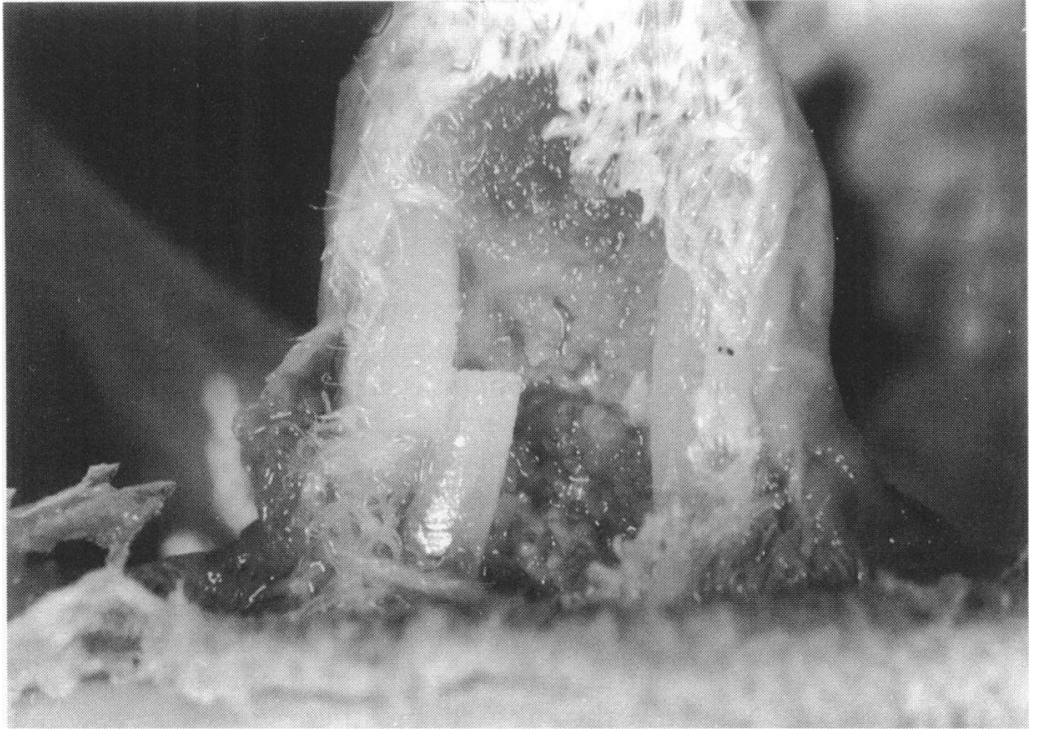

Figure 4 Detailed view of a fractured stent post in an aortic Wessex bioprosthesis.

Table 5 Indications for reoperation

\begin{tabular}{|c|c|c|c|}
\hline \multirow[b]{2}{*}{ Indication } & \multicolumn{3}{|l|}{ Group } \\
\hline & $\begin{array}{l}M V R \\
(n=46)\end{array}$ & $\begin{array}{l}A V R \\
(n=72)\end{array}$ & $\begin{array}{l}\text { MultiVR } \\
(n=32)\end{array}$ \\
\hline Structural failure & 7 & 5 & 6 \\
\hline Endocarditis & 1 & 3 & - \\
\hline Prosthetic thrombosis & 2 & - & 1 \\
\hline Periprosthetic leak/haemolysis & 2 & 2 & 2 \\
\hline
\end{tabular}

MVR, mitral valve replacement; AVR, aortic valve replacement; MultiVR, multiple valve replacement.

recorded in 11 patients (table 3). Haemolysis appeared in one MultiVR patient, periprosthetic leak in two MVR, four AVR, and two MultiVR patients, and both haemolysis and periprosthetic leak in one AVR and one MultiVR patient. Actuarial estimates of freedom from non-structural dysfunction at nine years of follow up $(70 \% \mathrm{CI})$ were 95 (3)\% for MVR, 72 (17)\% for AVR, and 84 (8)\% for MultiVR.

REOPERATION

Thirty one patients required explantation of

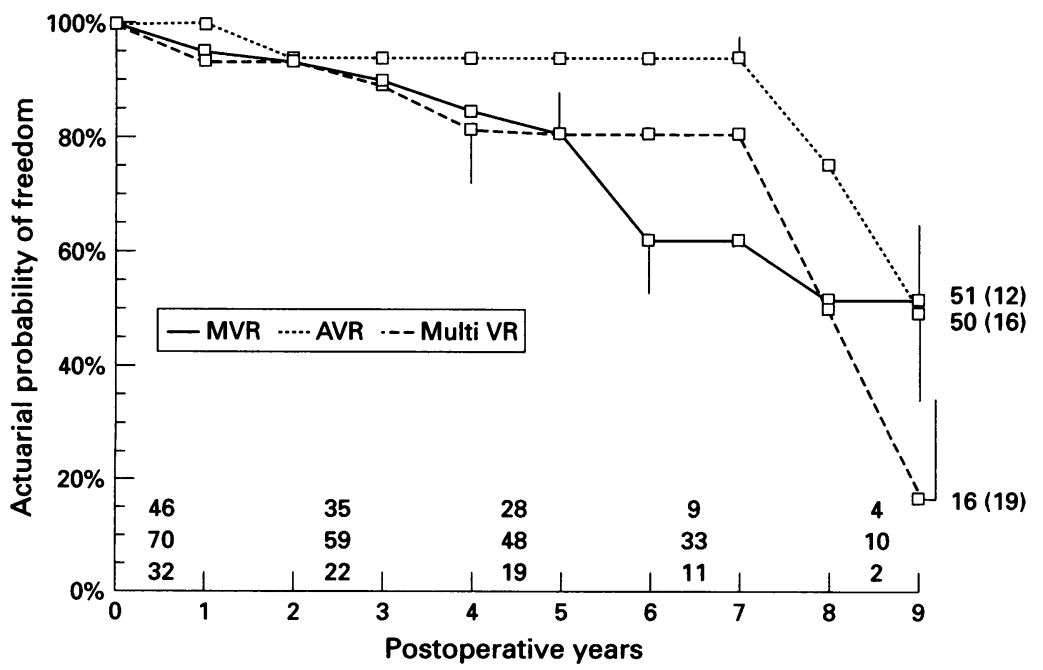

Figure 5 Freedom from reoperation. Actuarial probability at 9 years' follow up. Error bars $=70 \%$ confidence interval. their prostheses (table 3), the indications for reoperation being shown in table 5 . Actuarial probabilities of freedom from reoperation at nine years $(70 \% \mathrm{CI})$ were $51(12) \%$ for MVR, 50 (16)\% for AVR, and 16 (19)\% for MultiVR (fig 5).

FUNCTIONAL STATUS AND VALVE RELATED MORTALITY AND MORBIDITY

The great majority of the patients were in NYHA (New York Heart Association) class III or IV preoperatively $(96 \%, 44 / 46$ of the MVR; $63 \%$, $45 / 72$ of the AVR; $87 \%, 28 / 32$ of the MultiVR). Postoperatively, all the surviving non-reoperated patients were in NYHA class I or II except for two patients in the MVR group and four in the AVR group, who remained in class III. Actuarial estimates of freedom from any valve related morbidity or mortality at 9 years $(70 \% \mathrm{CI})$ were $31(10) \%$ for MVR, 21 (11)\% for AVR, and 7 (9)\% for MultiVR (fig 6).

\section{Discussion}

The Wessex bioprosthesis was designed in the early 1980s, with the aim of developing a totally European porcine heart valve that would take advantage of the knowledge and technical refinements available at the time in this field of research. The device was made available for clinical use in $1982 .{ }^{1}$ During its manufacturing process, selected porcine aortic roots were fixed in glutaraldehyde to a final concentration of $0.2 \%$ and with a head pressure of $50 \mathrm{~mm} \mathrm{Hg}$, and mounted on flexible plastic stents. A strip bias of glutaraldehyde treated porcine parietal pericardium, with its visceral surface exposed, was applied to the outflow edge of the device, purportedly to reduce the eventual abrasion associated to the contact at this level between the leaflets and the free edges and the frame. ${ }^{1}$ The cast stent was made out of Hostafom C27021, an acetylcopolymer not previously used in prosthetic heart valve manufacture and chosen for its in vitro creep and mechanical fatigue resistance properties.

Initial in vitro studies showed a satisfactory hydrodynamic performance, comparable to other bioprostheses available at the time, ${ }^{5}$ and the short term follow up studies were encouraging. ${ }^{26}$ However, to our knowledge no further follow up research has been carried out on this valve, not even by the original investigators. Our study is thus the first attempt to determine the mid to long term clinical performance of this bioprosthesis, and we believe that the results obtained-despite the fact that the series is not a large one-are significant enough as to justify this report.

The first relevant feature in our series is an unusually high incidence of thromboembolic phenomena and valve thrombosis. The incidence of this complication is significantly higher than has been reported for other porcine bioprostheses, ${ }^{7-11}$ and even higher than the figures obtained with some modern mechanical prostheses. ${ }^{12-15}$ Also, the results with other porcine bioprostheses in this 


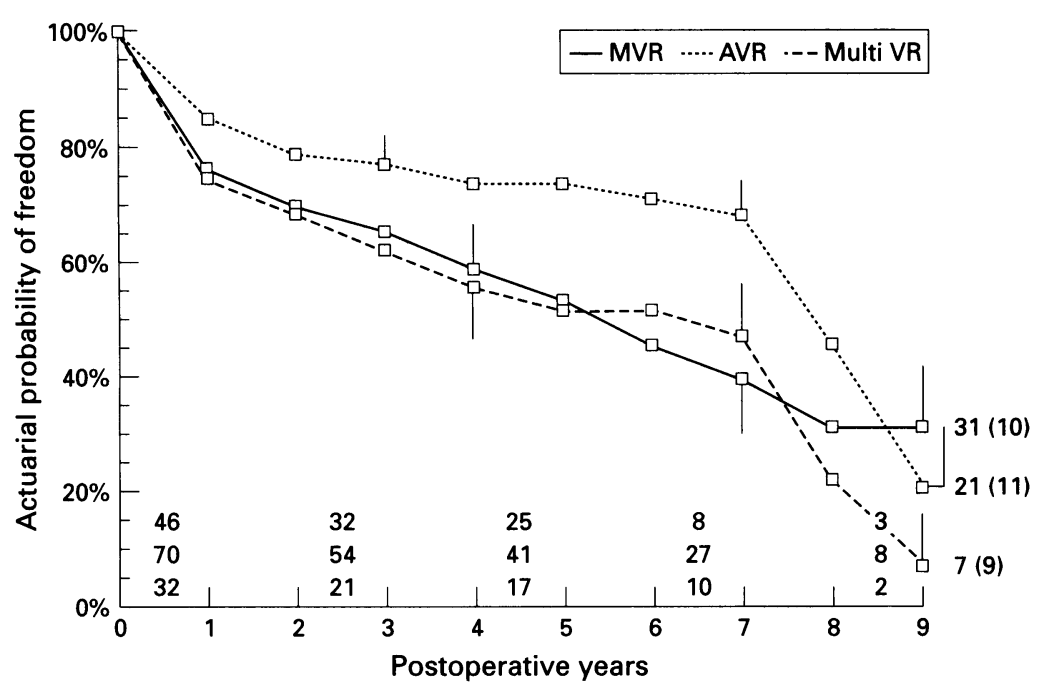

Figure 6 Freedom from any valve-related morbidity or mortality. Actuarial probability at 9 years' follow up. Error bars $=70 \%$ confidence interval.

respect are, in our experience and with a similar patient population, better than those obtained with the Wessex device. ${ }^{81617}$ These differences in thrombogenicity of different porcine bioprostheses, implanted within the same institution and time frame to similar patient populations, seem to show that the Wessex prosthesis is the agent responsible for the increased number of thromboembolic events in the present series. Furthermore, valve thrombosis has been a rare finding with porcine bioprostheses in our experience and that of others, but in this group reaches incidences of $1.0,0.3$, and 0.7 events per 100 patient-years, for MVR, AVR, and MultiVR, respectively, which are on the high range of the rates obtained with many mechanical valve devices. ${ }^{18}$

Another striking feature of our series is the early appearance of structural failure as the result of primary tissue degeneration (tear, perforation, thickening, or mineralisation of the biological tissue in the absence of infection). In the present study, the actuarial freedom from structural failure ranges in the different patient cohorts between $82 \%$ and $100 \%$ at five years and between $12 \%$ and $50 \%$ at nine years. We and others have seldom found instances of structural deterioration of porcine bioprostheses, either mitral or aortic, before the sixth year of follow up in adults. ${ }^{818}$ Also, the nine year actuarial rates of freedom from this phenomenon range in different series between $60 \%$ and $90 \%$ for MVR, between $70 \%$ and $95 \%$ for AVR, ${ }^{7-1119}$ and between $50 \%$ and $70 \%$ for MultiVR. ${ }^{811}$ Although dissimilarity in primary tissue failure risk factors (younger age, valve position, gender, valve size) could be relevant when comparisons are made with other researcher's results, these factors are similar when the reference experience is our own, as with the Medtronic Hancock II porcine valve. ${ }^{16}$ The origin of this high incidence of primary tissue failure is uncertain, and it could be related to the tissue management, fixation process, or the valve design. The suboptimal durability of this prosthesis implies a significantly higher rate of reopera- tions, the actuarial probability of freedom from this complication at nine years ranging, in our experience, between $16 \%$ in the MultiVR group and $51 \%$ in the MVR group.

Fracture of the stent in a Wessex prosthesis was first reported by $\mathrm{Au}$ and Campanella in 1989. ${ }^{20}$ This is an extraordinarily rare complication of modern biological valve prostheses. In our experience with this device, it appears to be more than an incidental finding and we believe it constitutes a true and relatively frequent mode of structural failure of these valves. All specimens presenting stent ruptures were explanted for reasons other than the rupture itself. This phenomenon was unnoticed in the pre-explantation echocardiograms and it was made evident only when analysing in detail the explanted specimens. The actuarial probability of freedom from frame rupture found in this study $(66 \%$ at nine years of follow up) probably underestimates the actual incidence of this phenomenon since: (1) the rupture is often subclinical and the estimation is based on explanted specimens, which may or may not represent the whole population of valve carriers; and (2) only 17 of the 40 explants $(42.5 \%)$ were available for study, which means that, had the whole population of explanted valves be studied, a larger number of broken stents may have been detected.

We conclude that the Wessex porcine bioprosthesis is associated with high rate of valve related complications such as thromboembolic phenomena, prosthetic structural deterioration, and rupture of the stent. The Wessex porcine bioprosthesis is no longer available for clinical use but, since there is a high morbidity/mortality associated with this device, we believe that all carriers of these valves deserve a very close follow up.

1 Reece IJ, Anderson JD, Wain WH, Carr K, Toner PG, Tindale W, et al. A new porcine bioprosthesis: in vitro and in vivo evaluation. Life Support Systems 1985; 3:207-27.

2 Reece IJ, Wheatley DJ, Munro JL, Wisheart JG, Keen G, Ross JK, et al. Early results with the Wessex porcine bioprosthesis in 245 patients. In: Bodnar E, Yacoub M, eds.
Biologic and bioprosthetic valves. New York: Yorke
Medical Books, $1986: 760-7$. Medical Books, 1986:760-7. Edmunds LH, Clark RE, Cohn LH, Miller DC, Weisel
RD. Guidelines for reporting morbidity and mortality $\mathrm{RD}$. Guidelines for reporting morbidity and mortality
after cardiac valvular operations. $\mathcal{F}$ Thorac Cardiovasc Surg 1988;96:351-3.

4 Kaplan EL, Meier P. Nonparametric estimation from incomplete observations. F Am Stat Assoc 1958;53:457-81.

5 Santalla A, Rodriguez-Bailon I, Calleja M, Tercedor L, Cervera S, Lara J, et al. Clinical and hemodynamic assesment of the Wessex and Hancock II bioprostheses. Midterm follow-up. Rev Esp Cardiol 1992;45:361-4.

6 Drury PJ, Monro JL, Shore DF, Lamb RK, Ross JK. A six year comparison of Carpentier-Edwards and Wessex bioprosthetic porcine valves. International Symposium on Surgery for Heart Valve Disease Programme. London, 1989:144.

7 Akins CW, Carroll D, Buckley M, Daggett WM Hilgenberg $\mathrm{AD}$, Austen WG. Late results with Carpentier-Edwards porcine bioprosthesis. Circulation 1990;82(suppl 4):65-74.

8 Bernal JM, Rabasa JM, Cagigas JC, Echevarría JR, Carrión MF, Revuelta JM. Valve-related complications with the Hancock I porcine bioprosthesis: a twelve to fourteenyear follow-up study. $\mathcal{F}$ Thorac Cardiovasc Surg 1991;
101:871-80.

9 Burdon TA, Miller DC, Oyer PE, Mitchell RS, Stinson EB, Starnes VA, et al. Durability of porcine valves at fifteen years in a representative North American populateen years in a representative North American
tion. $\mathcal{F}$ Thorac Cardiovasc Surg 1992;103:238-52.

10 Gallo I, Nistal F, Blasquez R, Arbe E, Artiñano E. Incidence of primary tissue failure in porcine biopros-
thetic heart valves. Ann Thorac Surg 1988;45:66-70.

11 Pelletier LC, Carrier M, Leclerc Y, Lepage G, deGuise P, 
Dyrda I. Porcine versus pericardial bioprostheses: a comparison of late results in 1,593 patients. Ann Thorac Surg parison of late resu

12 Arom KV, Nicoloff DM, Kersten TE, Northrup WF, Lindsay WG, Emery RW. Ten year's experience with the St Jude Medical valve prosthesis. Ann Thorac Surg 1989;47:831-7.

13 Arom KV, Nicoloff DM, Kersten TE, Northrup WF, Lindsay WG, Emery RW. Ten year follow-up study of patients who had double valve replacement with the $S$ Jude Medical prosthesis. I Thorac Cardiovasc Surg 1989; 98:1008-16.

14 Flemma RJ, Mullen DC, Kleinman LH, Werner $\mathrm{PH}$ Anderson AJ, Weirauch E. Survival and event-free analysis of 785 patients with Björk-Shiley spherical-disc valves at 10 to 16 years. Ann Thorac Surg $1988 ; 45: 258-72$.

15 Nitter-Hauge $S$, Abelnoor M. Ten-year experience with the Medtronic Hall valvular prosthesis. Circulation 1989; 80(suppl 1):43-8.

16 Nistal JF, Bernal JM, Gil F, Hurle A, Revuelta JM. Five to nine year follow-up of Hancock II porcine bioprostheses in the isolated mitral and aortic positions. Proceedings of the VI International Symposium on Cardiac Bioprostheses. Vancouver, 1994:70. 17 Duran CMG, Gallo I, Ruiz B, Revuelta JM, Ochoteco A. A thousand porcine bioprostheses revisited. Do they conform with the expected pattern? In: Cohn LH, Galluci V, eds. Cardiac bioprostheses. Proceedings of the Second International Symposium. New York: Yorke Medical Books, 1982:35-41.

18 Grunkemeier GL, Starr A, Rahimtoola SH. Prosthetic heart valve performance: long term follow-up. In: O'Rourke RA, McCall D, eds. Current problems in cardiology. St Louis: Mosby Year Book Inc, 1992:329-406.

19 Jones EL, Weintraub WS, Craver JM, Guyton RA, Cohen $\mathrm{CL}$, Corrigan VE, et al. Ten-year experience with the porcine bioprosthetic valve: interrelationship of valve survival and patient survival in 1,050 valve replacements. Ann Thorac Surg 1990;49:370-84.

$20 \mathrm{Au} \mathrm{J}$, Campanella C. Mitral prosthetic valve regurgitation due to stent fracture of a porcine bioprosthesis. Thorax 1989;44:236-7. 